Original article

\title{
Entry and initial spread of COVID-19 in India: Epidemiological analysis of media surveillance data, India, 2020
}

\author{
Nuzrath Jahan ${ }^{\mathrm{a}}$, Polani Rubeshkumar ${ }^{\mathrm{a}, *}$, Mathan Karuppiah ${ }^{\mathrm{a}}$, Irene Sambath ${ }^{\mathrm{a}}$, \\ Muthappan Sendhilkumar ${ }^{a}$, Kumaravel Ilangovan ${ }^{a}$, Roopavathi Ongesh ${ }^{a}$, \\ Manikandanesan Sakthivel ${ }^{a}$, Raju Mohankumar ${ }^{a}$, Muthusamy Santhosh kumar ${ }^{a}$, \\ Parasuraman Ganeshkumar ${ }^{\mathrm{a}}$, Manickam Ponnaiah ${ }^{\mathrm{a}}$, Prabhdeep Kaur ${ }^{\mathrm{a}}$

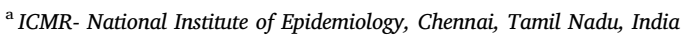

\section{A R T I C L E I N F O}

\section{Keywords:}

Cluster

COVID-19

Epidemiology

India

SARS-CoV-2

\begin{abstract}
A B S T R A C T
Background: India reported first laboratory-confirmed case of coronavirus disease 2019 (COVID-19) on 30 January from Kerala. Media surveillance is useful to capture unstructured information about outbreaks. We established media surveillance and described the characteristics of the COVID-19 cases, clusters, deaths by time, place, and person during January-March 2020 in India.

Methods: The media surveillance team of ICMR-National Institute of Epidemiology abstracted data from public domains of India's Central and State health ministries, online news and social media platforms for the period of January 31 to March 26, 2020. We collected data on person (socio-demographics, circumstances of travel/ contact, clinical and laboratory), time (date/period of reported exposures; laboratory confirmation and death) and place (location). We drew epidemic curve, described frequencies of cases by age and gender. We described available details for identified clusters.

Results: As of March 26, 2020, India reported 694 (Foreigners = 45, 6\%) confirmed COVID-19 cases (Attack rate $=0.5$ per million population) and 17 deaths (Fatality $=2.5 \%$ ) from 21 States and 6 Union Territories. The cases were higher among 20-59 years of age (60 of 85) and male gender (65 of 107). Median age at death was 68 years (Range: $38-85$ years). We identified 13 clusters with a total of 63 cases and four deaths among the first 200 cases.

Conclusion: Surveillance of media sources was useful in characterizing the epidemic in the early phase. Hence, media surveillance should be integrated in the routine surveillance systems to map the events specially in context of new disease outbreaks.
\end{abstract}

\section{Introduction}

A novel coronavirus (SARS-CoV-2) that originated from Wuhan, China, has been linked to the outbreak of severe respiratory infections in humans first reported on December 31, 2019. Globally, there were $13,876,411$ confirmed cases and 593,087 deaths in 216 countries as on July $18,2020 .{ }^{1}$ Overall, 92 countries had reported community transmission, 75 countries including India had reported clusters of cases and 27 countries reported sporadic cases. ${ }^{1}$ With increased availability of data, the case definitions, management, and control measures have been refined, though this was not the case during the early phase of the pandemic. Most of the initially reported cases had a travel history from Wuhan, China. ${ }^{2}$ Subsequently, countries such as Thailand, Singapore,
South Korea, Japan, USA, and France reported coronavirus disease 2019 (COVID-19 cases). ${ }^{3}$ The majority of the cases in the initial phase belonged to the age group 30-69 years (78\%) and male (51\%). ${ }^{4}$ The case-fatality rate of COVID-19 varied from $2.3 \%$ in China to $9 \%$ in Italy. ${ }^{4,5}$ The median incubation period of COVID-19 was five days, and the basic reproductive number was $2.2 .^{6}$

On January 30, India reported first laboratory-confirmed case of COVID-19 from Kerala with history of travel from Wuhan, China. The first three cases were reported at the end of January and early February 2020. Subsequently, there were no cases between February 4 and March 1, 2020. Beginning March 2, 2020, cases began increasing across various Indian States. ${ }^{7}$ Currently, clusters have been reported from different settings across the country including but not limited to.

\footnotetext{
* Corresponding author. ICMR- National Institute of Epidemiology, R 127, Second main road, TNHB, Ayapakkam, Chennai, 600 077, India.

E-mail address: rubeshkumar@nieicmr.org.in (P. Rubeshkumar).
} 


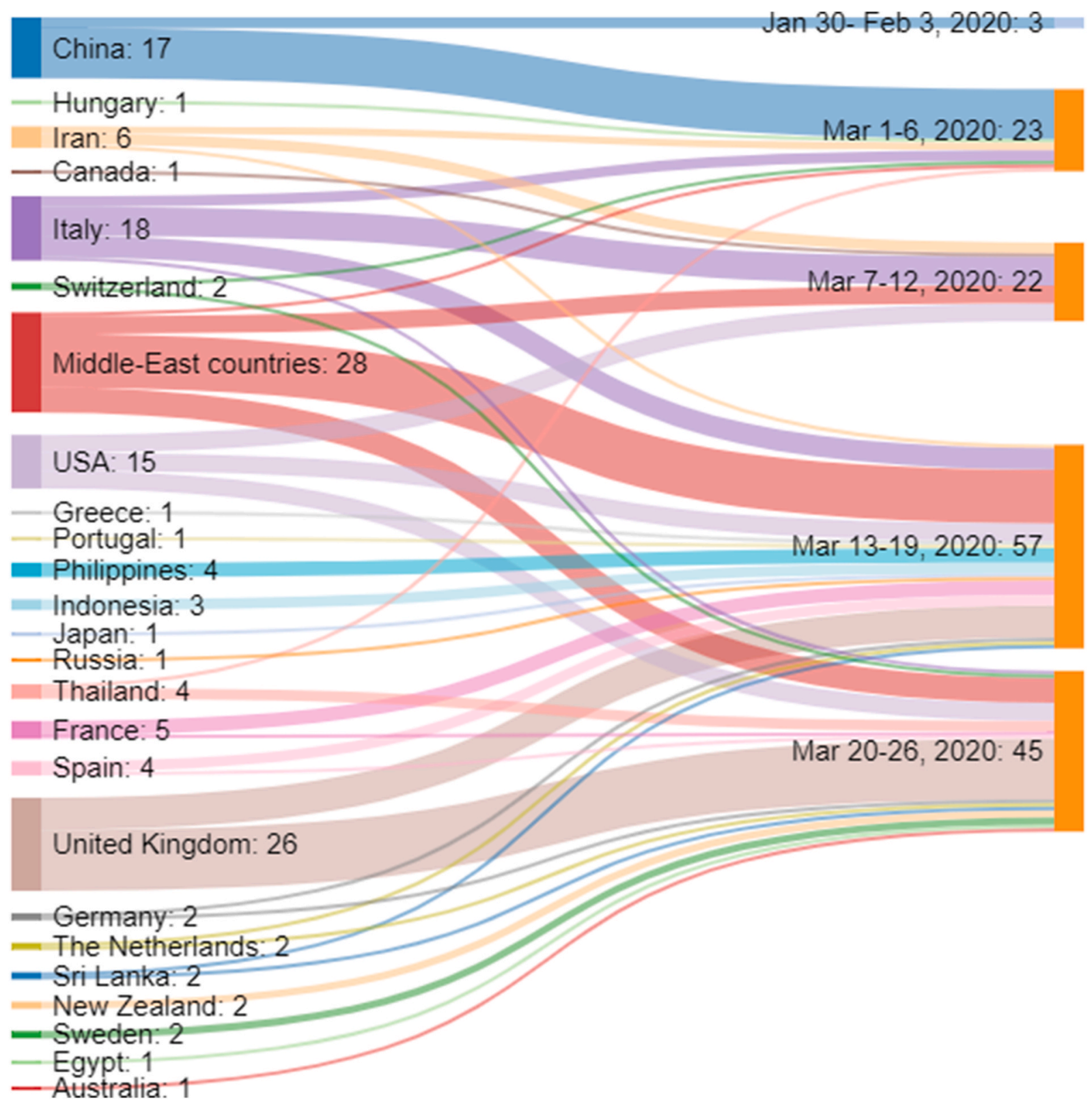

Fig. 1. Distribution of COVID-19 cases by their country of origin and by the week of arrival to India.

Currently, national level dashboard, ${ }^{8}$ state level media bulletins, ${ }^{9,10}$ syndromic data from sentinel sites and laboratories are used to describe the status of COVID19 in India. ${ }^{11,12}$ But in the early stages of epidemic, such data sources were limited. Descriptive epidemiology of clusters reported by media played a vital role in understanding the sources and spread of disease. Early pandemic response and preparedness, especially in the context of low-and-middle-income countries requires harnessing the existing resources including monitoring of media sources ${ }^{13}$ and real-time analysis of data to guide public health policies and interventions.

We established media surveillance in the early phase of the pandemic and collected data from multiple sources to describe the characteristics of the COVID-19 cases, deaths and clusters of cases by time, place and person during January-March 2020.

\section{Methods}

Case definition: We defined a confirmed case of COVID-19 as "case of laboratory-confirmed COVID-19 infection irrespective of signs and symptoms" as per the National Centre for Disease Control, India guidelines. $^{14}$

Definition of cluster: We operationally defined cluster as two or more secondary cases with an epidemiological linkage with that of an index case. The epidemiological linkage is in terms of exposure within incubation period time.

\subsection{Data sources and period}

We relied on COVID-19 specific information available from the public domains. We reviewed home pages of Union and State health ministries. We accessed online news sources and social media platforms such as Facebook, Twitter, Instagram and LinkedIn. Our reference period was January 31 to March 26, 2020.

Data collection: We retrieved data on information on COVID-19 cases and deaths. We consulted the above-mentioned data sources for collecting case-specific data on socio-demographics (place of residence, type, age gender, location), laboratory confirmation, clinical (symptoms, hospitalization details, outcomes such as death or discharge) and 
Table 1

Characteristics of COVID-19 cases, India, January 30- March 26, 2020 $(\mathrm{N}=694)$.

\begin{tabular}{llll}
\hline Characteristics & & \# COVID-19 case & $\%$ \\
\hline Age (years) & $<9$ & 5 & 1 \\
& $10-19$ & 11 & 2 \\
& $20-39$ & 139 & 20 \\
& $40-59$ & 87 & 13 \\
& $60-79$ & 69 & 10 \\
& $\geq 80$ & 8 & 1 \\
Nex & NA & 375 & 54 \\
& Female & 117 & 17 \\
Nationality & Male & 204 & 29 \\
& NA & 373 & 54 \\
History of International Travel & Indian & 649 & 94 \\
& Foreign nationals & 45 & 6 \\
& Yes & 150 & 22 \\
& No/Not known & 544 & 78 \\
\hline
\end{tabular}

NA - Not available.

exposure details (history of international travel contact) (Supplementary appendix I). Similar to information collected for cases, we collected information on index, primary and secondary cases and their socio-demographics, laboratory, type and circumstances of exposure(s), and clinical details.

Data analysis: We described the frequencies of characteristics of cases and deaths by age, gender, residence, type of exposure. We used the population denominators to calculate attack rate. We drew epidemic curve by date of reporting of COVID-19 cases. We used QGIS (Quantum Geographic Information System) ${ }^{15}$ to map the distribution of number of COVID-19 cases by Indian States. We described characteristics of identified clusters in terms of time, place, history of travel, number, and type of contacts and outcomes. Based on consulted data sources, we mapped timelines of cases/clusters with reference to location and exposure circumstances.

\section{Results}

\subsection{Cases reported during reference period}

As of March 26, 2020, India had reported 694 confirmed COVID-19 cases (attack rate $=0.5$ per million population) and 17 deaths related to COVID-19 (case-fatality rate $=2.5 \%$ ). We could extract information on time, place and person for 82 of these reported cases.

\subsection{Description of cases}

Among the reported 694 COVID-19 cases, 45 (6\%) were foreign nationals, and $150(20 \%)$ reported travel to the COVID-19 affected countries. In the first week of the epidemic, there were 17 cases among travelers from China. During the subsequent two weeks, the majority were among the travelers from Middle-East countries, Italy, and the USA. The travelers from the United Kingdom constituted most of the cases in the fourth week. The figure (Fig. 1) shows the distribution of COVID-19 cases by their country of origin and by the week of arrival to India.

Age and gender data were available for less than half (46\%) of the cases. The COVID-19 cases were higher among the age group 20-59 years and male gender (Table 1). Only three cases were reported at the end of January and early February 2020. Subsequently, cases started reporting until mid-March 2020 . We witnessed a sharp increase after March 21, 2020 (Fig. 2). Among the 28 Indian States and 8 Union Territories (UTs), 21 States and 6 UTs reported COVID-19 cases. As of March 26, 2020, the five Indian states with the maximum number of COVID-19 cases were Kerala, Maharashtra, Karnataka, Gujarat, and Telangana (Fig. 3). The Indian States such as Arunachal Pradesh, Sikkim, Tripura, Nagaland, Jharkhand, Meghalaya did not report any COVID-19 cases.

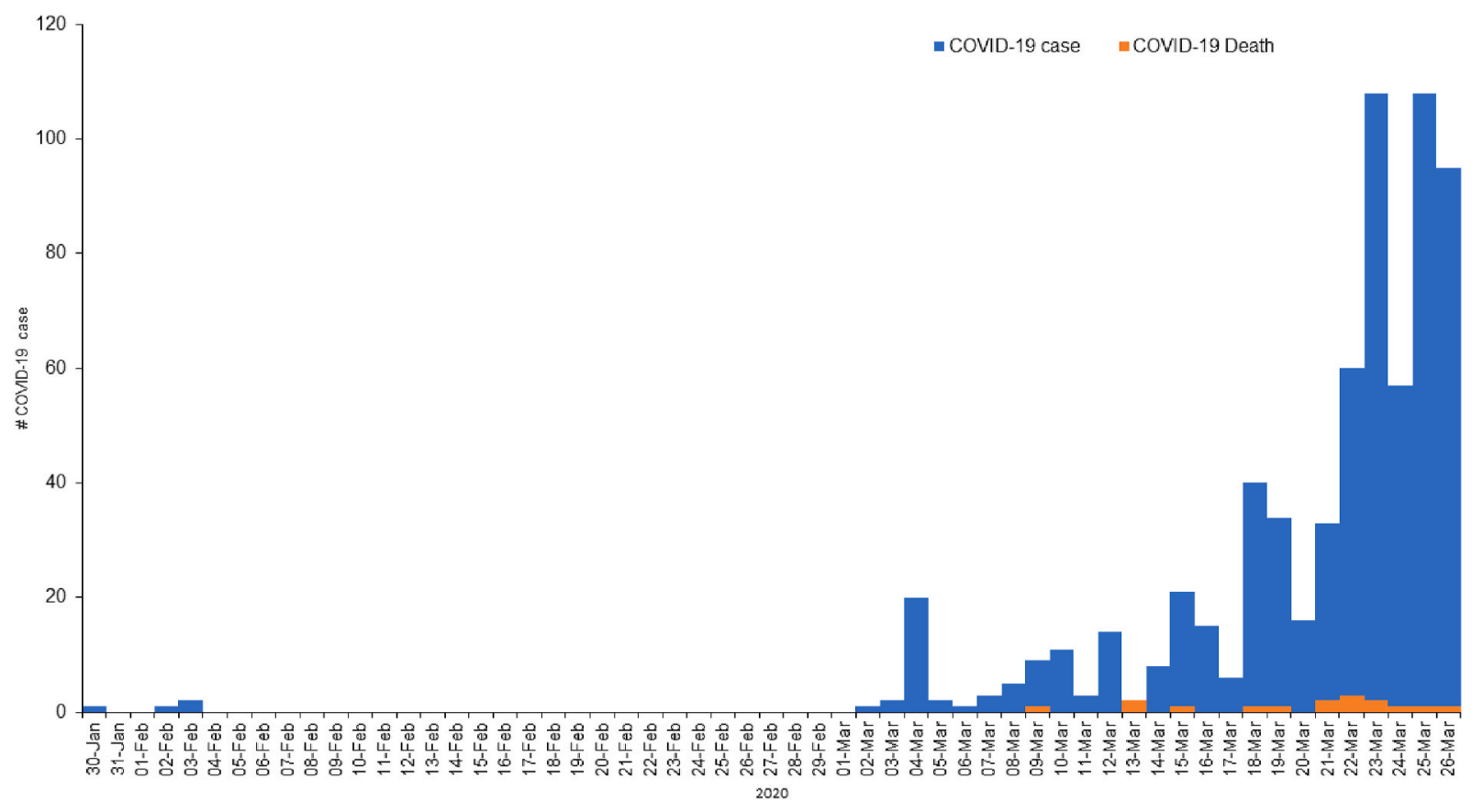

Fig. 2. COVID-19 cases and Deaths by date of reporting, 30 Jun-26 Mar 2020. 


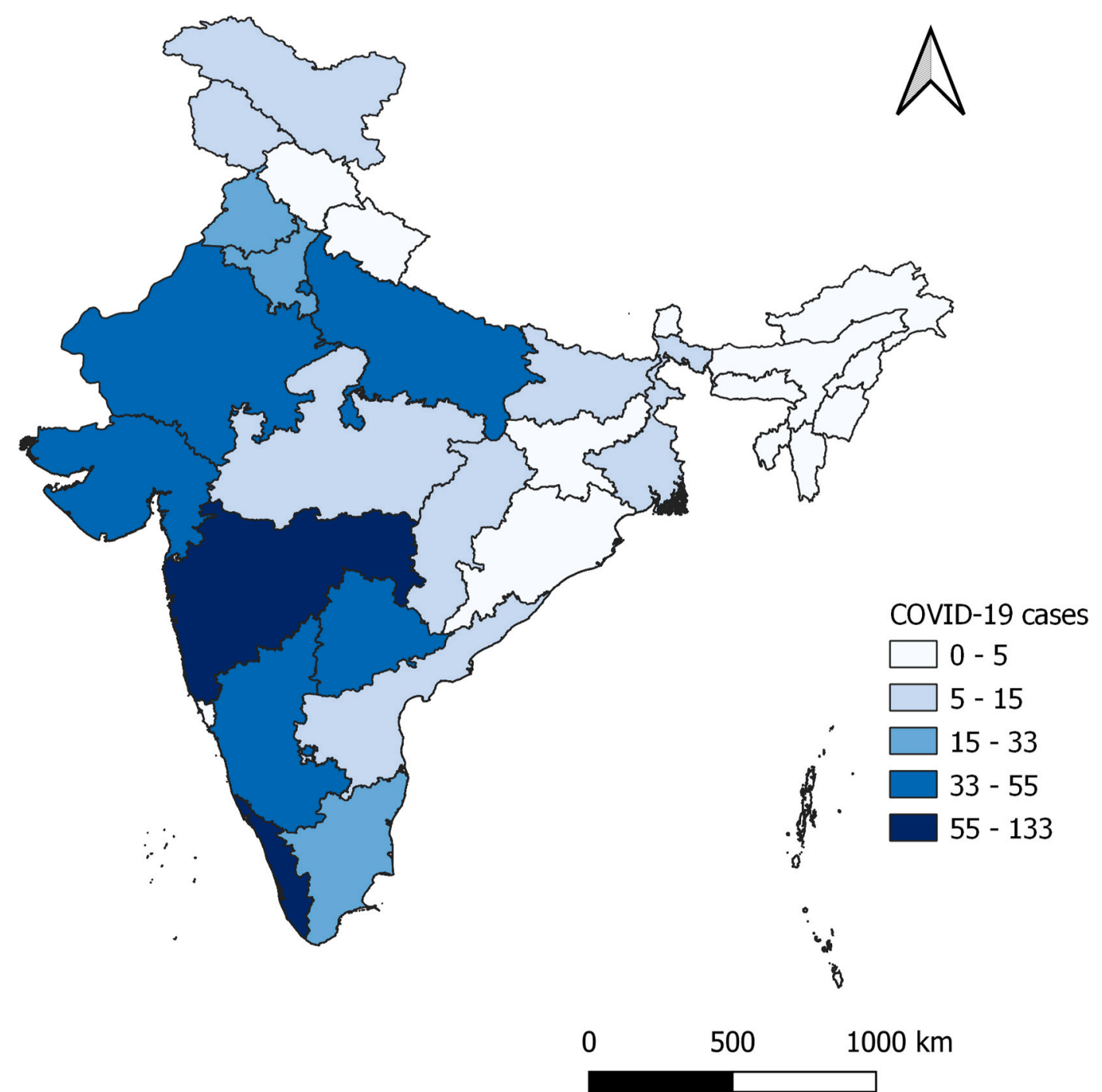

Fig. 3. COVID-19 cases by States, India, Jan- Mar 2020.

\subsection{Description of deaths}

There were 17 deaths related to COVID-19 in India as of March 26, 2019. All the deceased were aged above 60 years except three (Median $=68$ years; Range $=38-85$ years). According to Indian Ministry of Health, two of these deaths were not considered as deaths due to COVID-19 since they had co-morbidities after they recovered from COVID-19. In addition, test results of the two case-patients were declared after their death (Table 2). In terms of history, 11 of them had history of international travel and one had contact with confirmed case. Of the reported deaths, three had history of travel to Delhi in relation to religious congregation during first two weeks of March 2020.

\subsection{Description of clusters}

Of the first 200 reported cases, we could identify 13 clusters contributing to 63 cases from eight Indian States across the country (Fig. 4). Of the 63 cases, there were four deaths, of which two were index cases and two were contacts of index cases. The index cases in all these clusters had history of international travel from the countries where the outbreak was ongoing. The countries from where the index cases travelled were China (Wuhan), Italy, Iran, UAE, Canada, Saudi Arabia, and the USA. Ten of the 13 clusters had positive household contacts. Other types of contacts who became positive were fellow travelers, coworkers, or healthcare workers (Table 3).

\section{Discussion}

We used data from media surveillance to summarize descriptive epidemiology of COVID-19 from India. When a new disease is introduced in the country, surveillance systems have to adapt to capture appropriate information regarding the disease. During this phase, media surveillance can help fill gaps in the information and can trigger action to confirm the reported events. Case-based reports in media reduced with the wider spread of disease and availability of data on the national and state websites.

The outbreak started late in India as there were very few imported cases from China in January 2020. However, as the outbreak spread to other countries during February 2020, there were imported cases from various countries. The initial screening strategy of Indian Ministry of Health included passengers from China and subsequently expanded to include international travelers with ongoing pandemic. The rapid spread of the outbreak to several countries posed a practical challenge in the implementation of temperature screening for a large number of passengers. Given the limitations, nearly $46 \%$ of cases might have been missed. ${ }^{16,17}$ Besides, the availability of testing only in a few labs in the early phase of the outbreak was a barrier to rapid scaling up of testing in the initial weeks leading to low detection of cases. 


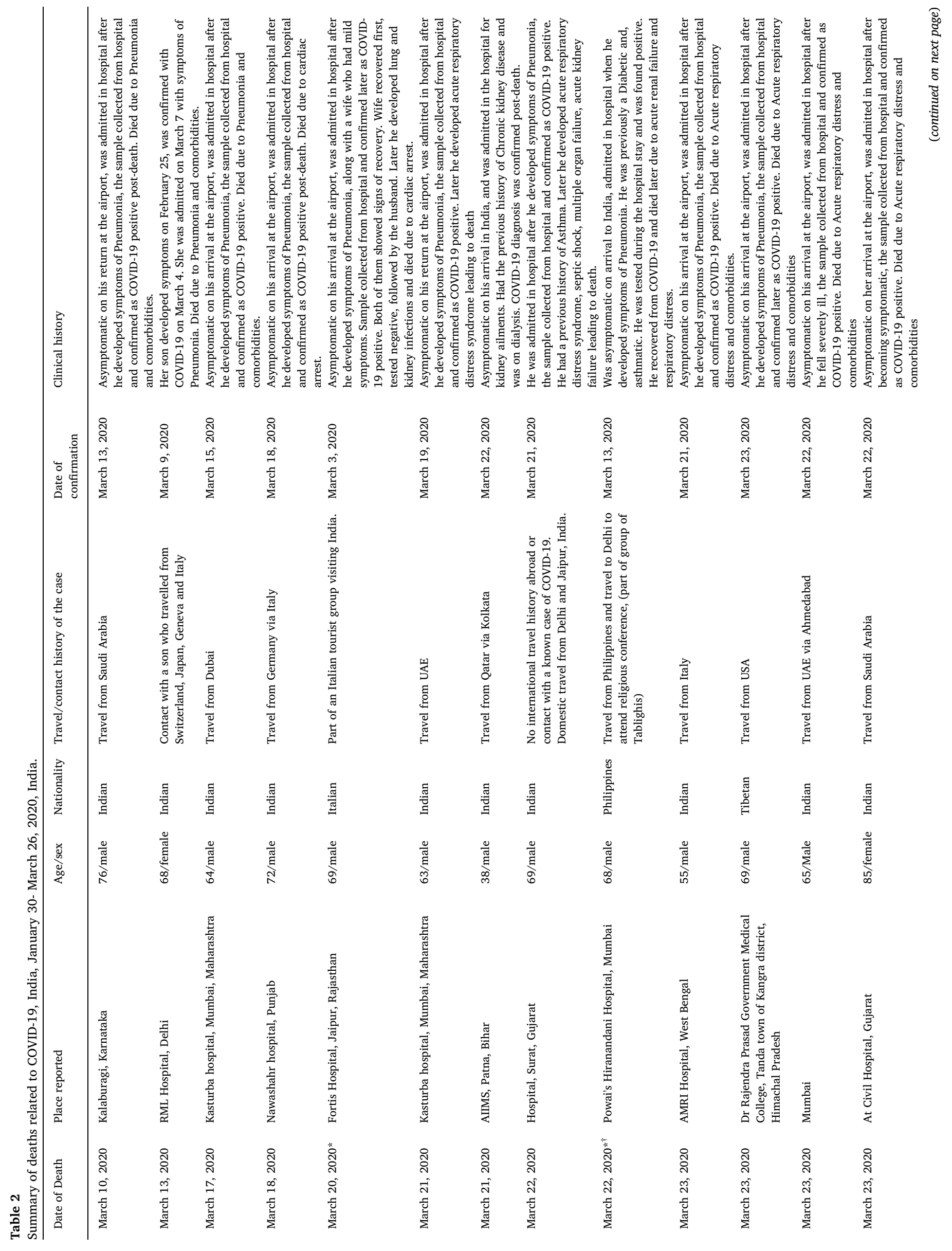


Apart from the International travelers, most of the cases and deaths were reported among the close family members. Evidence from other countries also suggests that the attack rate among household contacts could vary from $3 \%$ to $31 \%{ }^{18}$ The higher attack rate of household contacts could be attributed to the prolonged contact time in the infectious period. The knowledge regarding the type of contacts that turned positive was essential to inform the testing policies and rational use of resources for contact tracing. ICMR modified the testing policy on March 20, 2020, to include all close high-risk contacts including household members. ${ }^{19}$

We used number of deaths as indicator of severity of the pandemic. Most of the deaths were among cases above 60 years of age and with a history of comorbidities. During the early stages of the epidemic in Wuhan, China, half of the COVID-19 cases were reported among persons with comorbidities namely hypertension, diabetes, and coronary heart disease. ${ }^{20} \mathrm{~A}$ systematic review and meta-analysis of 8 studies reported the higher odds ratio (OR) of comorbidities such as hypertension $(\mathrm{OR}=2.36)$, respiratory diseases $(\mathrm{OR}=2.46)$ and cardiovascular diseases $(\mathrm{OR}=3.42)$ among the severe COVID-19 cases than non-severe cases. ${ }^{21}$ Zhou et al. reported the higher odds of death among the COVID-19 deaths with comorbidities such as coronary heart disease $(\mathrm{OR}=21.4)$, diabetes $(\mathrm{OR}=2.9)$ and hypertension $(\mathrm{OR}=3.1){ }^{22}$ The early risk assessment helped states to device preemptive measures targeting population at risk and triage policies for COVID-19 care. $^{23}$

We used data from government sources in the public domain and media sources. We might have missed the information released by state governments in the local languages and local media briefings. We could not review all the media sources and did not review the local language media. Therefore, we might have missed the clusters or details about deaths. We cannot ascertain the accuracy of the information, although we reviewed multiple media reports for details of each cluster and death.

\section{Conclusion}

COVID-19 outbreak in India started with imported cases from multiple countries, and most of the clusters were among household contacts. Most of the deaths were among travelers or close contacts of travelers. The media surveillance data demonstrated the importance of unstructured information for initial epidemiological analysis to characterize the pandemic. Data from media surveillance can supplement existing surveillance systems and fill gaps specially in context of a new disease which may not be fully captured in the routine surveillance systems. The data from media surveillance need further field-based investigations to confirm the introduction and spread of the disease in a district or state.

\section{Financial support and sponsorship}

The study has been sponsored by ICMR- National Institute of Epidemiology, Chennai.

\section{Authors' contribution}

PK, PG, PR, NJ, MP, SM, RM involved in conceptualization, data analysis, drafting and revising and approval of the manuscript. NJ, PR, MK, IS, MS, KI, RO, SMinvolved in data co llection and analysis, revising and approval of the manuscript.

\section{Declaration of competing interest}

None. 


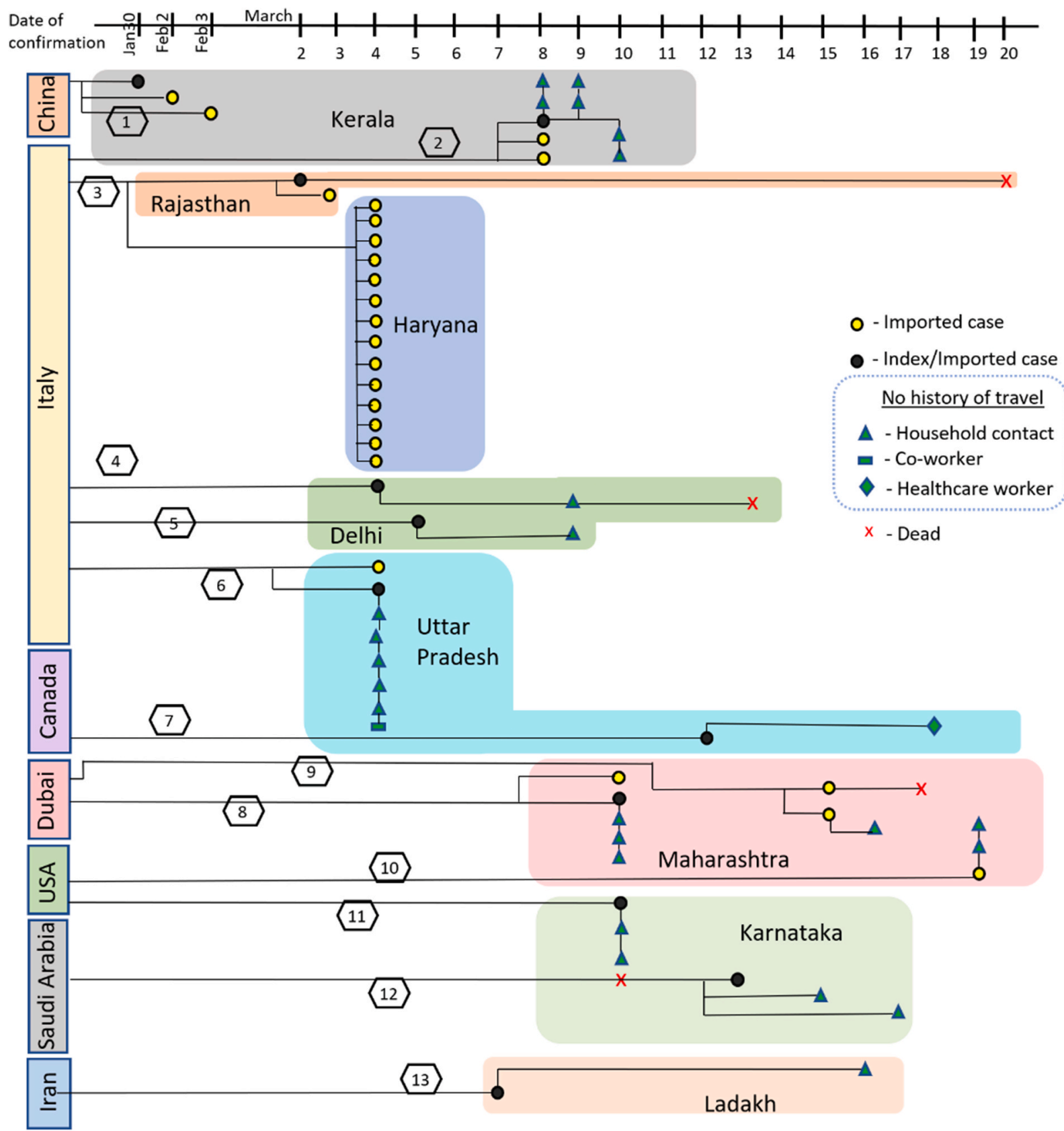
8. Pune family cluster 1
9. Pune family cluster 2
10. Mumbai family cluster
11. Bengaluru family cluster
12. Kalaburagi family cluster
13. Ladakh family cluster

Fig. 4. Different clusters of COVID-19 cases, India, Jan-Mar 2020. 


\section{Appendix A. Supplementary data}

Supplementary data to this article can be found online at https:// doi.org/10.1016/j.cegh.2020.10.008.

\section{References}

1. COVID-19 situation report-178. https://www.who.int/docs/default-source/ coronaviruse/situation-reports/20200716-covid-19-sitrep-178.pdf?sfvrsn = 28ee165b_2.

2. Epidemiological data from the nCoV-2019 outbreak: early descriptions from publicly available data - novel 2019 coronavirus/nCoV-2019 genomic epidemiology - virological. http://virological.org/t/epidemiological-data-from-the-ncov-2019outbreak-early-descriptions-from-publicly-available-data/337.

3. COVID-19 situation report-6. https://www.who.int/docs/default-source/ coronaviruse/situation-reports/20200126-sitrep-6-2019-ncov.pdf?sfvrsn = beaeee0c4.

4. The Epidemiological Characteristics of an Outbreak of 2019 Novel Coronavirus Diseases (COVID-19) - China. 2020; 2020http://weekly.chinacdc.cn/en/article/id/ e53946e2-c6c4-41e9-9a9b-fea8db1a8f51.

5. Livingston E, Bucher K. Coronavirus disease 2019 (COVID-19) in Italy. J Am Med Assoc. 2020;323(14):1335. https://doi.org/10.1001/jama.2020.4344https:// jamanetwork.com/journals/jama/fullarticle/2763401.

6. Li Q, Guan X, Wu P, et al. Early transmission dynamics in wuhan, China, of novel coronavirus-infected pneumonia. N Engl J Med. 2020 Mar 26;382(13):1199-1207.

7. Ministry of health and family welfare | GOI RSS. https://www.mohfw.gov.in/.

8. \# IndiaFightsCorona COVID-19. https://mygov.in/covid-19/.

9. \#TelanganaFightsCorona (COVID-19) - government of Telangana. https://covid19. telangana.gov.in/.

10. StopCoronaTN - Health \& Family Welfare Department. Government of Tamil nadu. https://stopcorona.tn.gov.dhcp.in/.

11. States asked to ramp up surveillance for Severe Acute Respiratory Infections or Influenza-like illnesses to detect hidden infections. Hindu. 2020 May 12https://www. thehindu.com/news/national/coronavirus-states-asked-to-ramp-up-surveillance-forsevere-acute-respiratory-infections-or-influenza-like-illnesses-to-detect-hiddeninfections/article31569205.ece.

12. ICMR readies new Covid surveillance survey. https://indianexpress.com/article/ india/icmr-readies-new-covid-surveillance-survey-6402480/.

13. A world at risk: annual report on global preparedness for health emergencies. https://apps.who.int/gpmb/assets/annual_report/GPMB_annualreport_2019.pdf.

14. Disease Alerts :: national Centre for disease control (NCDC). https://ncdc.gov.in/ index4.php?lang $=1$ \&level $=0$ \&linkid $=127 \&$ lid $=432$.

15. QGIS Development Team. QGIS geographic information system. Open source geospatial foundation project. http://qgis.osgeo.org; 2019.

16. Eurosurveillance | Effectiveness of airport screening at detecting travellers infected with novel coronavirus. https://www.eurosurveillance.org/content/10.2807/15607917.ES.2020.25.5.2000080; 2019.

17. Indian Journal of Medical Research - Prudent Public Health Intervention Strategies to Control the Coronavirus Disease. http://www.ijmr.org.in/downloadpdf.asp?id = 281325;type = 2\#; 2019.

18. Burke RM. Active Monitoring of Persons Exposed to Patients with Confirmed COVID19 - United States, January-February 2020. https://www.cdc.gov/mmwr/ volumes/69/wr/mm6909e1.htm.

19. ICMRstrategyforCOVID19testinginIndia. https://www.mohfw.gov.in/pdf/ ICMRstrategyforCOVID19testinginIndia.pdf.

20. Chen N, Zhou M, Dong X, et al. Epidemiological and clinical characteristics of 99 cases of 2019 novel coronavirus pneumonia in Wuhan, China: a descriptive study. Lancet. 2020 15;395(10223):507-513.

21. Yang J, Zheng Y, Gou X, et al. Prevalence of comorbidities in the novel Wuhan coronavirus (COVID-19) infection: a systematic review and meta-analysis. Int $J$ Infect Dis. 2020 May;94:91-95. https://doi.org/10.1016/j.ijid.2020.03.017 PMID: 32173574 ; PMCID: PMC7194638.

22. Zhou F, Yu T, Du R, et al. Clinical course and risk factors for mortality of adult inpatients with COVID-19 in Wuhan, China: a retrospective cohort study. Lancet. 2020 Mar 28;395(10229):1054-1062.

23. Verma A, Maruvada G, Agur R. Policy Response of Union and State Governments. 2020; 2020 India. 